\title{
Impact of Personalized Social Media Advertisements on Consumer Purchase Intention
}

\author{
Mehta REENA ${ }^{\star}$, Kulkarni UDITA ${ }^{\star \star}$
}

\begin{tabular}{l}
\hline \multicolumn{1}{c}{ A R T I C L E I N F O } \\
\hline Article history: \\
Accepted June 2020 \\
Available online August 2020 \\
\hline JEL Classification \\
M30, M31 \\
Keywords: \\
Consumer behavior, Digital \\
marketing, Personalized \\
advertisements, e-commerce, \\
Online marketing
\end{tabular}

A B S T R A C T

The prime objective of this paper was to understand how personalized ads on social media platforms, influence consumer's purchase intention. Increased interaction with personalized ads influence the consumer's psyche and behaviour to make a purchase in absence of an internal stimulus. Special emphasis is thus laid upon studying the direct impact of personalized ads (frequency of display, relevance and usefulness of advertisements) encountered on social media platforms and the consumers' intent of purchase in conjunction with their perception of personalized ads and privacy controls. The data was collected from 110 respondents through an indirect admission of questionnaire. Our findings suggest that the frequency of personalized ad exposure, ad's perceived relevance and usefulness to consumers, concerns with respect to privacy controls and, cognitive and affective attitude significantly impact the perception and subsequent purchase intention of consumers.

(C) 2020 EAI. All rights reserved.

\section{Introduction}

With the boom of digital technologies, and subsequent proliferation of social media as a tool to reach a larger consumer base, marketers are now relying heavily on personalized marketing through mobile marketing, e-mail marketing, social media marketing, etc. The incentive is direct interaction, more organic reach, heightened response, easier data collection and effective consumer targeting. Although traditional marketing is still a go-to option, the Indian market's most prominent segment is Social Media Advertising with a forecasted market volume of USD 3,770 million in the year 2020 alone (Statista, 2020). It is estimated that there are a whopping 3.5 billion users ( $45 \%$ of world population) of social media. Since consumers spend extensive durations of time (average of 3 hours daily) on social media daily, marketers find it easier and rewarding to design ad campaigns that focus on customer engagement to ramp up their ads' effectiveness (Oberlo.in, 2020). Couple this growing trend to the increasing impact of influencer marketing, inducting personalized ads through social media feed of consumers, is deemed to be the most effective way of inducing brand or product recall.

The way consumers experience advertisements on social media are crucial in defining the engagement outcomes as desired by advertisers. When a brand decides to design an ad campaign whose aim is to disrupt the consumers' flow and seek attention towards the product, service or brand; conceptualization, designing and execution of ads become indispensable (Johansson and Wengberg, 2017). The average attention span of users on social media is alleged to be 08 seconds ("the Goldfish Effect"), which lends marketers with a narrow range of time to execute their intended communication and simultaneously impact the way consumers perceive it (Mack, 2015). This perception develops into a purchase intention, provided the advertisement is able to entice the receivers of this ad.

The rationale for studying the perception of personalized advertisements on social media and its impact on consumer purchase intention rose from the understanding that a mere exposure of ad communication in a limited few seconds, can leave a lasting influence on consumers, thus shaping their purchase decisions and perception of brand personality. These factors not only result in commemoration of profits, but also in long term contribute to brand value build up. There have not been many studies focusing on personalized social media advertising driven perception based consumer purchase intention. We aim to explore further into this topic and aid understanding by comparing personalized advertising on multiple social media platforms.

On the other hand, firms are facing a challenge in terms of increasing negative outcomes from personalized ads on social media. This can be attributed to heavy personalization that's led to consumers 
"freaking out" over the accuracy of relevance and intent of the ad (John et al., 2018). Personalized ads are slowly being termed as arrows made of personal intrusion, mining of consumer data (interests, habits, preferences, usage patterns) and sly modes of permission marketing (Karimi et al., 2017)s. Hence, this study can shed some light on how social media users perceive personalized ad communication. We have primarily focused on understanding how personalized ads interact with our respondents, parameters that can potentially challenge acceptance or rejection by consumers, and consumers' purchase intention with regards to products and/or services they encounter through personalized ads.

\section{Literature review}

\subsection{Social Media Marketing}

The integration of electronic marketing in various forms has brought about a renaissance in the way marketers approach advertising. The biggest advantage of online marketing is its ability to be measured. Even in the days of pure online marketing, the click-through-rates of banner advertisements on Google homepages or various webpages was capable of being measured accurately (Chourasiya, 2017). This advantage led to the development of enhanced algorithms, enabling marketers to target the audience better. This measurement has been crucial in furthering the ability of online marketing, and eventually digital marketing, to aid personalization of ads on e-marketing platforms. The highlight of social media networks is the sheer volume of user generated content (UGC) which is voluntarily disbursed by the user (Maoyan et al., 2017). This data adds to the dynamism of social media marketing as these data points are purely organic, representative of the consumer base, are consumer centric and free of intermediary influence.

The surge in social media advertising is attributed to the plausibility of consumers openly communicating on social media platforms for purposes of expressing feelings, sharing experiences with fellow users, actively engaging in marketer-driven ad campaigns, etc. Many firms are investing into building online communities, that if handled and nurtured well, might become brand loyalist, further accelerating the Word-of-Mouth advertising (Quick, 2020). Based on a study conducted by Balakrishnan et al. (2014), several online marketing communications, like, e-WOM or online communities, play a primary role in promotion of the brand itself, or its products and services; with consumers encouraging the interactive nature of social media advertising to eventually achieve their own purchase intentions by helping brands through suggestions.

\subsection{Personalized Advertising on Social Media}

A core component of any advertising campaign is its ability to influence consumer behaviour by impacting consumer attitude and eventually driving brand loyalty by increasing the consumers' purchase intention. Ad targeting is a phenomenon wherein the advertisement in question is the starting point. On the contrary, personalization of advertisements begin with a consumer so as to create "personalized" ads that fit the consumer's preferences best. The readily available consumer data on internet opened up a new opportunity for advertisers to target consumers selectively by personalizing the communication (Bleier and Eisenbeiss, 2015).

Online Behavioral Advertising (OBA) utilizes the digital footprint of potential consumers acquired by collating data of online activity, viz., websites visited, streaming platforms accessed, content search history, video preferences, etc. The increased relevance and effectiveness of ads are deemed to be crucial by industry experts. Boerman et al. (2017) conducted their research through Theoretical Modelling to test for OBA User Acceptance and Resistance. Their results are concurrent with several other research studies, where personalization of advertisements is viewed as a double edged sword, with a fine line between harmless utilization of available data and personal privacy violation.

Although personalization of advertisements garner consumers' attention more frequently, social media users are hypothesized to have developed a phenomenon referred to as "banner blindness", which helps them to subconsciously weed out information blasts and promotional advertisements. This cognitive ignorance of consumers is well documented in a study conducted by Kasper et. al. (2017) where they measured the eye movements of consumers to determine whether the displayed ad is fixating enough or not. They point out that demographics can result in increased self-relevance of personalized ads, an observation important for marketers.

When we consider the interaction of advertising efforts and their impact on consumer attitudes, Belch and Belch (2012) state that there exists three attitudinal components or stages which define a tricomponent model:

(i) Cognitive Component which encapsulates an individual's belief towards an object

(ii) Affective Component which depicts the individual's feelings (positive or negative) towards the object

(iii) Behavioural Component which defines the individual's readiness to respond to objects in the form of behaviour

Carrillat et al. (2014) suggested a positive attitude of consumers towards Facebook messages, employed for the purpose of studying patterns of responses towards recruitment messages on the platform. 
Another study by Duffett, R. (2014) found that FB advertising had a positive impact on South African Millennials' purchase intention. On the contrary, a study by Yu J. (2011) depicts that personalization of email as a marketing tool is optimistic, but that many consumers preferred to delete the mails without having opened them. This hints at the possibility that consumers think of personalized e-mails as unethical, with the parent company having violated privacy principles.

From the firm's perspective, analysis of consumer purchase intention based on social media marketing is pivotal in decision making and devising support mechanisms for e-commerce (Maoyan et al., 2017). Hashim et al. (2018) studied the mobile advertising message content to analyse its fit with a correlation model that suggests the impact on consumer purchase intention. There are two determinant factors evident from this study, namely, the positive attitude towards purchase intention and the length of time the advertisement runs for. Similar results regarding consumers' perception towards personalized ads are noted by Gaber et al., (2019), where they extruded four important factors: (i) credibility of the ad (ii) informativeness of the ad (iii) entertainment quotient and (iv) lack of irritation. There is a larger risk for companies who wish to address the consumer privacy concerns, as they shall continue to use the consumer data for ad personalization. Duplexity in handling privacy concerns can make the consumers respond less or negatively to personalized ads. To bypass this backlash, data-rich websites like social networks, have introduced privacy control measures that can be regulated by users (Tucker, 2013).

\section{Research Methodology}

\subsection{Selection of Social Media Platforms}

Based on the Indian user base and potential growth prospects, six major social media apps were selected. All these apps are lucrative platforms for advertisements as they are highly popular in India. (Sannam S4, 2020).

\begin{tabular}{|l|l|r|l|l|}
\hline \multirow{4}{*}{$\begin{array}{c}\text { Social Media } \\
\text { Platform } \\
\text { Characteristics }\end{array}$} & Platforms & $\begin{array}{r}\text { User base in } \\
\text { India (in million) }\end{array}$ & Selection Criteria & Social Media Advertising Potential \\
\cline { 2 - 5 } & Facebook & 260 & Country with highest user base & Most effective and preferred platform \\
\cline { 2 - 5 } & Instagram & 80 & High proportion of 18-24 year old users & Focus on younger consumer base \\
\cline { 2 - 5 } & Youtube & 265 & Equal usage across demographics & Ads are primary source of revenue \\
\cline { 2 - 5 } & Linkedln & 62 & $\begin{array}{l}\text { Important for Influencer Marketing, } \\
\text { owns SlideShare }\end{array}$ & Huge user base of professionals \\
\cline { 2 - 5 } & TikTok & 466 & Country with highest user base & Fastest growth (44\%) in new user acquisition \\
\cline { 2 - 5 } & Twitter & 11.45 & $\begin{array}{l}\text { Highest engament with high profile } \\
\text { individuals }\end{array}$ & Fairly novel but has higher engagement \\
\hline
\end{tabular}

Table 1 Selection Criteria of Social Media Platforms

We excluded certain apps like Snapchat, Tumblr, Pinterest, etc. on grounds of lower popularity, which can be a shortcoming of our study. Although, it's not practically feasible for us to expand our study to include all social media apps, as new apps are being launched every other day. Hence, we chose siz representative apps that drive thorough traction.

\subsection{Data Collection and Analysis}

The primary data collection was performed using the Convenience Sampling Technique. This nonprobability sampling technique offers the flexibility to define a sample through simple convenience, wherein the researcher is not required to select a representative sample of elements with expert judgement (Lavrakas, 2008). An online survey form was circulated amongst a random selection of population. A total of 110 responses were recorded. The sample population was representative of multiple age groups and both genders. An online survey tool was used so as to concur with the convenience sampling technique. The nature of the research is of descriptive type, and thus allows to limit the sample size to a smaller population $(\mathrm{N}=110)$, with the freedom of posing researcher-driven questions.

The questions were structured in a formal to informal way to provide the respondents with flow. The demographically significant questions were recorded so as to generate an analysis of the representative population set. Few questions posed as behaviour or preference recording tools, thus enabling "dependency" analysis. The research was thus both qualitative and quantitative in nature. The responses procured via the survey were extracted into a Microsoft Excel sheet. For the entire analysis, IBM's Statistical Package for Social Sciences (SPSS) Software, Version 25, was employed. The data was analysed at a confidence level of 95\% ( $\alpha=$ 0.05). The statistical significance for each test was recorded in order to accept or reject the null hypothesis and proceed with the analysis results. The qualitative data analysis was based on Descriptive tests (CrossTab) and percentage calculations. The quantitative data was subjected to various tests including CrossTab, Regression analysis, Correlation analysis and Factor Analysis. 


\subsection{Research Questions}

The research questions were broadly classified as (a) perception of consumers regarding personalized advertisements, and (ii) impact on consumer purchase intention of personalized advertisements on social media platforms. Based on these objectives, the following hypothesis were proposed:

H1: Platform specific personalized advertisements have an impact on consumer purchase decisions

H2: Display frequency of personalized advertisements on social media platforms has a significant impact on consumers' purchase decision/intent

H3: Personalization of ads based on relevance and usefulness of products/services advertised has a significant impact on consumers' purchase intention

H4: Privacy concerns with respect to personalized ads on social media impact consumers' purchase intentions

H5: Consumers' perception regarding a brand using personalized advertisements on social media is significant in impacting their purchase intentions

\section{Results}

\subsection{Respondent Profile}

\begin{tabular}{|c|l|r|r|}
\hline \multirow{4}{*}{$\begin{array}{c}\text { Gender } \\
\text { distribution }\end{array}$} & Category & \multicolumn{1}{|c|}{ Count } & Percentage \\
\cline { 2 - 4 } & Females & 49 & $44.55 \%$ \\
\cline { 2 - 4 } & Males & 61 & $55.45 \%$ \\
\cline { 2 - 4 } & Total & $\mathbf{1 1 0}$ & $\mathbf{1 0 0 . 0 0 \%}$ \\
\hline \multirow{4}{*}{$\begin{array}{c}\text { Age } \\
\text { distribution }\end{array}$} & Category & Count & Percentage \\
\cline { 2 - 4 } & $18-24$ years & 35 & $31.82 \%$ \\
\cline { 2 - 4 } & 25-30 years & 33 & $30.00 \%$ \\
\cline { 2 - 4 } & 31-40 years & 7 & $6.36 \%$ \\
\cline { 2 - 4 } & $41-50$ years & 6 & $5.45 \%$ \\
\cline { 2 - 4 } & $51-60$ years & 27 & $24.55 \%$ \\
\cline { 2 - 4 } & Above 60 years & 2 & $1.82 \%$ \\
\cline { 2 - 4 } & Total & $\mathbf{1 1 0}$ & $\mathbf{1 0 0 . 0 0 \%}$ \\
\hline \multirow{4}{*}{$\begin{array}{c}\text { Education } \\
\text { Status }\end{array}$} & Category & Count & Percentage \\
\cline { 2 - 4 } & 12th/Diploma & 2 & $1.82 \%$ \\
\cline { 2 - 4 } & Graduate & 34 & $30.91 \%$ \\
\cline { 2 - 4 } & Post-Graduate & 69 & $62.73 \%$ \\
\cline { 2 - 4 } & Doctorate & 1 & $0.91 \%$ \\
\cline { 2 - 4 } & Professional & 4 & $3.64 \%$ \\
\cline { 2 - 4 } & Total & $\mathbf{1 1 0}$ & $\mathbf{1 0 0 . 0 0} \%$ \\
\hline
\end{tabular}

Table 2 Distribution of Gender, Age and Level of Education

The sample population of $\mathrm{N}=110$ had a fair distribution of both males (55.45\%) and females (44.55\%). The age distribution of the sample is reported in the adjoining table. It is noted that the sample population does not capture responses of an age group "Below 18 years", thus eliminating the possibility to comment on influence of personalized ads on social media on Gen $\mathrm{Z}$ consumers.

\subsection{Social Media Analysis}

Six most popular social media platforms were selected for this study. All of these platforms support personalized advertising, and have been previously claimed to have violated personal privacy of consumers by cross-sharing the consumer data with each other or other brands for better targeting of ads. YouTube was found to be the most used platform. Further, the respondents were asked regarding which platform displayed the most number of personalized

advertisements. The findings elucidated are graphically represented. $70.91 \%$ of the total sample population reported to have encountered personalized advertisements on social media platforms.

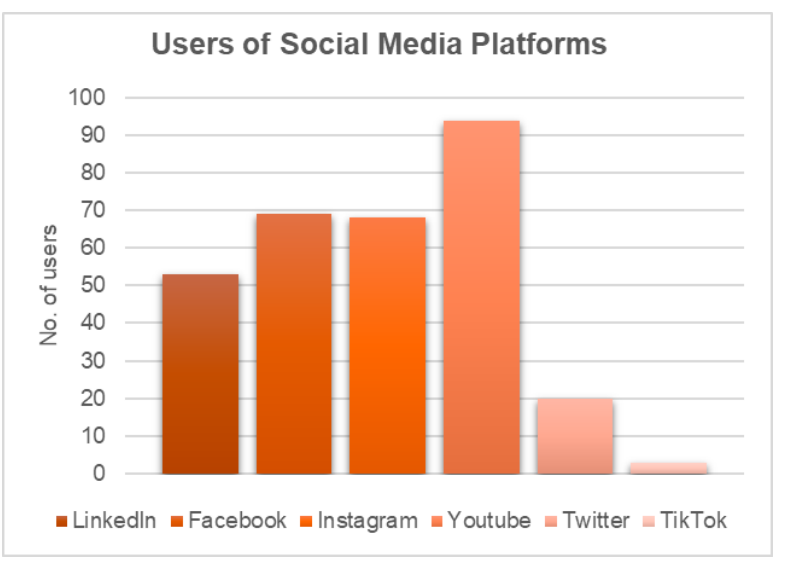

Figure 1a Social Media platform analysis

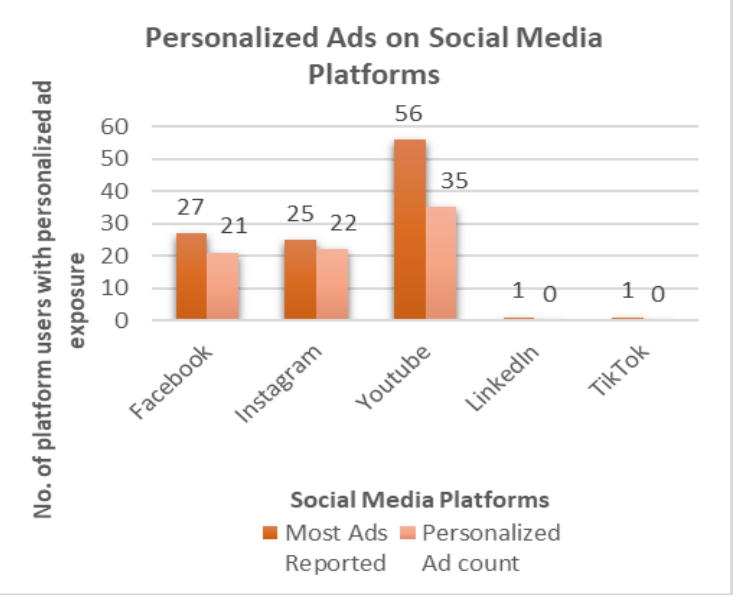

Figure 1b Personalized Social Media platform ad exposure

\subsection{Research Findings}

\subsubsection{Social Media Platforms' impact on Consumer Purchase Decisions (H1)}

To determine the impact of personalized ads on social media on consumer purchase decisions, two variables (personalized ad exposure on social media and extent of an urge to purchase the product on repeated exposure to these personalized ads) were analysed using Descriptive - CrossTab Analysis feature in the SPSS Software. The Pearson Correlation was found to be 0.047 , suggesting that the correlation between variables is extremely weak. 
The $p$-value for the correlation is 0.625 , indicating that the test is not statistically significant ( $p$-value $>0.05$ ). From the graph it is clear that a personalized ad exposure is not a strong factor for consumers to decide whether to purchase a product/service or not. The null hypothesis (H0) is hence accepted.

As a subset, the gender (male and female) dependent purchase intentions were elucidated. About $45.9 \%$ of male respondents reported to have "least purchase intent" when shown personalized ads on social media, repeatedly. On the contrary, $40.8 \%$ female respondents reported to have "strong purchase intent".

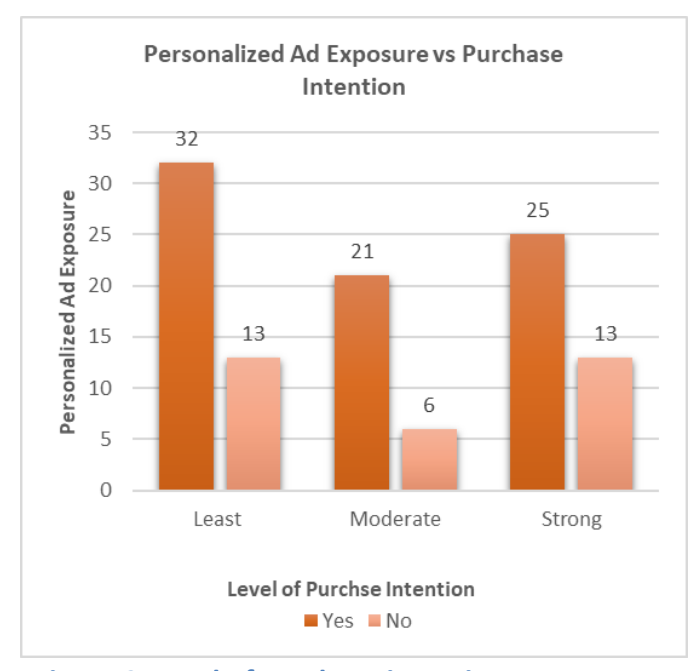

Figure 2 Level of purchase intention on exposure to personalized ad on social media

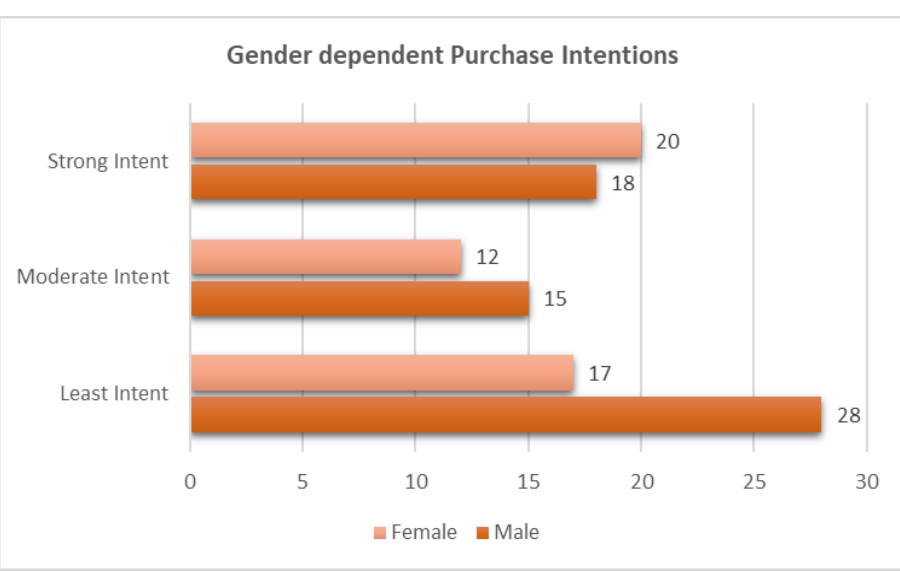

Figure 2 Gender dependent Consumer Purchase Intent

\subsubsection{Impact of frequency of personalized ads on social media, on Consumer Purchase Intention} (H2)

Only $70.9 \%$ of respondents agreed to have encountered personalized advertisements on some social media platform or the other. The survey mentioned four frequency slots $(0-1,2-5,6-10,>10$ times per day), of which, most common frequency of encountering personalized ads was 2-5 times/day.

The p-value of $0.012(<0.05)$ deems the test statistically significant, thus suggesting impact on purchase intention of frequency of personalized ads on social media.

\begin{tabular}{|c|c|c|c|c|c|c|c|}
\hline \multicolumn{8}{|c|}{ Regression Analysis - Model Summary ${ }^{\mathrm{b}}$} \\
\hline \multirow[b]{2}{*}{ Model } & \multirow[b]{2}{*}{$\mathrm{R}$} & \multirow[b]{2}{*}{ R Square } & \multirow[b]{2}{*}{$\begin{array}{c}\text { Adjusted R } \\
\text { Square }\end{array}$} & \multirow{2}{*}{$\begin{array}{l}\text { Std. Error } \\
\text { of the } \\
\text { Estimate }\end{array}$} & \multicolumn{3}{|c|}{ Change Statistics } \\
\hline & & & & & $\begin{array}{c}\text { R Square } \\
\text { Change }\end{array}$ & F Change & $\begin{array}{c}\text { Sig. F } \\
\text { Change }\end{array}$ \\
\hline 1 & $283^{\mathrm{a}}$ & 0.080 & 0.068 & 0.48441 & 0.080 & 6.611 & 0.012 \\
\hline \multicolumn{8}{|c|}{ a. Predictors: (Constant), Frequency_of_Ads } \\
\hline b. De & le: 1 & hase & & & & & \\
\hline
\end{tabular}

Table 3 Regression Analysis - Impact of frequency of ads on purchase intention

\subsubsection{Impact of relevance and usefulness of personalized ads on social media, on Consumer Purchase Intention (H3)}

The null hypothesis was

rejected as the p-value (2-tailed significance) was $0.000(<0.05)$. The two variables of relevance and usefulness, were reported to positively correlate to consumers' purchase intention, although the correlation is weak, as suggested by the Pearson Correlation value of 0.392 .

\begin{tabular}{|l|l|c|c|}
\hline \multicolumn{4}{|c|}{ Correlations } \\
\hline \multicolumn{2}{|c|}{} & Purchase_Intention & Relevance_Usefulness \\
\hline $\begin{array}{l}\text { Pearson } \\
\text { Correlation }\end{array}$ & Purchase_Intention & 1.000 & $\mathbf{0 . 3 9 2}$ \\
\cline { 2 - 4 } & Relevance_Usefulness & 0.392 & 1.000 \\
\hline \multirow{2}{*}{\begin{tabular}{l}
\multirow{2}{*}{ tailed) } \\
\hline \multirow{2}{*}{ N }
\end{tabular}} & Purchase_Intention & & $\mathbf{0 . 0 0 0}$ \\
\cline { 2 - 4 } & Relevance_Usefulness & 0.000 & 110 \\
\cline { 2 - 4 } & Purchase_Intention & 110 & 110 \\
\hline
\end{tabular}

Table 4 Correlation between relevance and usefulness of personalized ad with purchase intention

\subsubsection{Impact of privacy violation concerns on Consumer Purchase Intention (H4)}

About $45.45 \%$ respondents reported to be definitely concerned about personal privacy violations with respect to personalized advertisements as encountered on social media.

The CrossTabulation results highlight a common understanding that higher the privacy violation concern, lesser will be the consumers' purchase intention. This observation too bold in our findings. The Pearson Correlation between the two chosen variables of "Privacy Concerns" and "Purchase Intent" are 
moderately positive, but highly significant at 0.01 level. The p-value is 0.003 , much lesser than the required 0.05 . Hence, the null hypothesis is rejected.

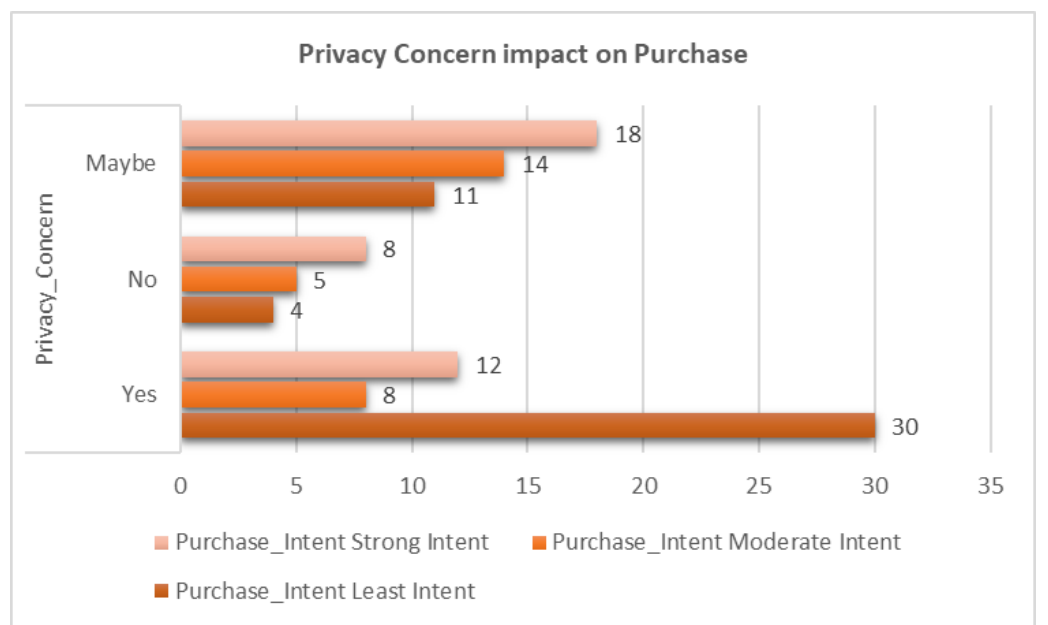

\begin{tabular}{|c|c|c|c|}
\hline \multicolumn{4}{|c|}{ Correlations } \\
\hline & & $\begin{array}{c}\text { Purchase_I } \\
\text { ntent }\end{array}$ & $\begin{array}{c}\text { Privacy_Co } \\
\text { ncern }\end{array}$ \\
\hline \multirow[t]{3}{*}{$\begin{array}{l}\text { Purchase_I } \\
\text { ntent }\end{array}$} & \begin{tabular}{|l|l|} 
Pearson \\
Correlation
\end{tabular} & 1 & $.281^{* *}$ \\
\hline & $\begin{array}{l}\text { Sig. (2- } \\
\text { tailed) } \\
\end{array}$ & & 0.003 \\
\hline & $\mathrm{N}$ & 110 & 110 \\
\hline \multirow[t]{3}{*}{$\begin{array}{l}\text { Privacy_Co } \\
\text { ncern }\end{array}$} & \begin{tabular}{|l|} 
Pearson \\
Correlation \\
\end{tabular} & $.281^{* *}$ & 1 \\
\hline & $\begin{array}{l}\text { Sig. (2- } \\
\text { tailed) }\end{array}$ & 0.003 & \\
\hline & $\mathrm{N}$ & 110 & 110 \\
\hline
\end{tabular}

Table 5 Correlation between purchase intent and privacy concerns

Figure 4 Impact of privacy concerns on purchase intent

\subsubsection{Impact of consumer perception of personalized social media advertisements on Consumer Purchase Intention (H5)}

The statements were analysed through Factor Analysis on SPSS Software, against a nominal variable, Gender. The good KMO measure of 0.689 indicates that the sample is adequate and can be put to further tests. The p-value of 0.00 (less than 0.05 ) allowed us to reject the null hypothesis as the test is statistically significant. We have compared the correlation values vertically. A prominent finding from this table is that two factors, namely, Worry and Irritation, consistently have low positive or negative values of correlation towards rest of the factors. On common sense grounds this finding stands true.

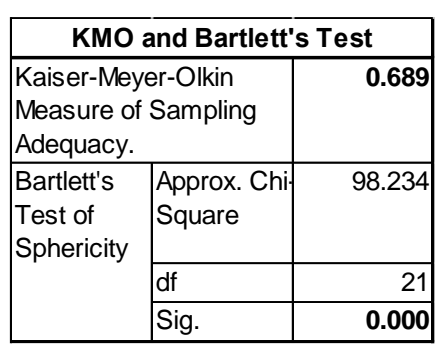

Table 6 KMO and Barlett's test

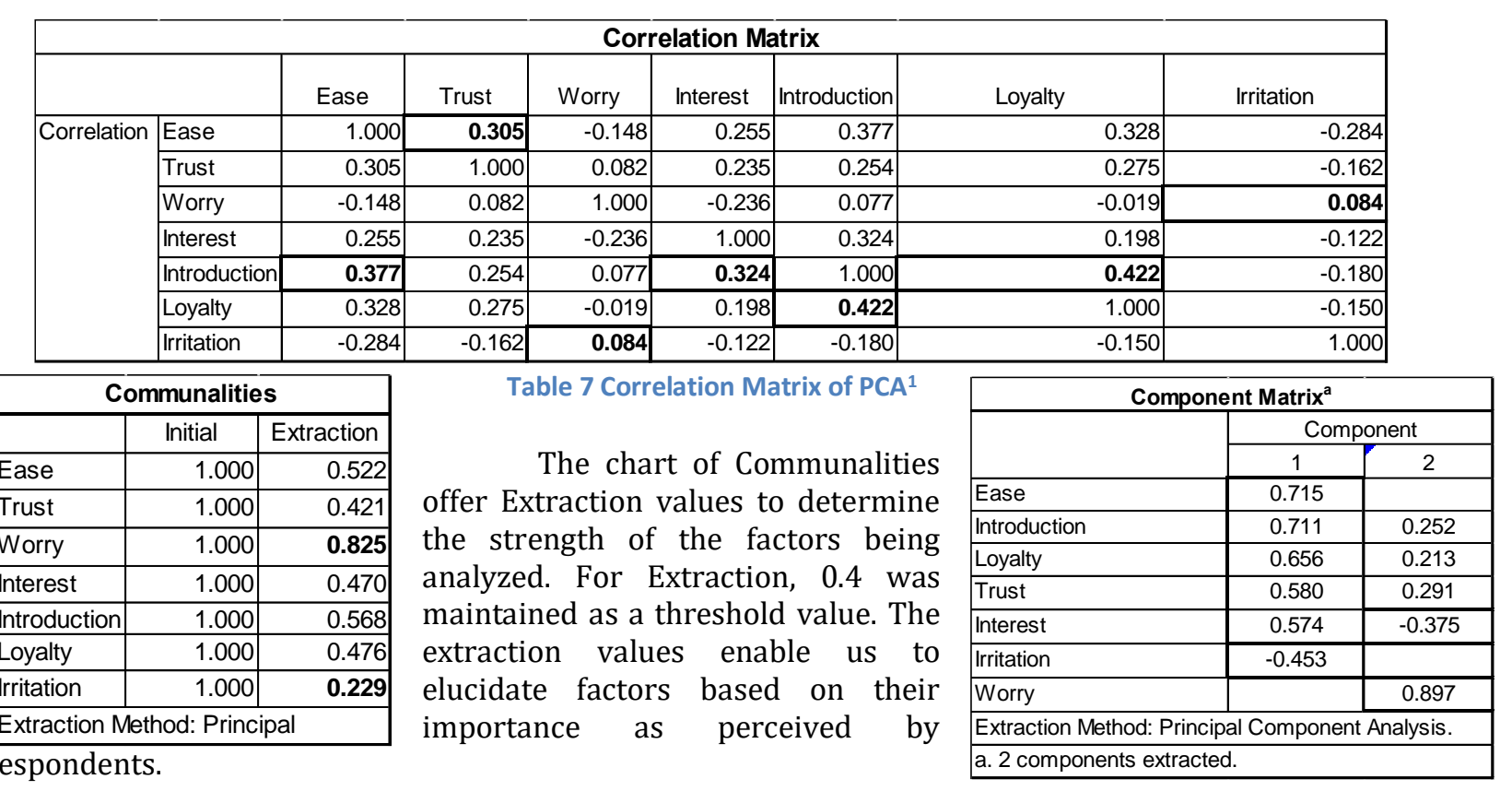

Table 8 Communalities of PCA

1Principal Component Analysis: Linear dimensionality reduction method performed in IBM SPSS, Software Version 25

Table 9 Component Matrix of PCA

The factor with highest value is "Worry", indicating that it's the most crucial factor for consumers with respect to personalized ads on social media. Similarly, the factor with lowest value is "Irritation", denoting that this factor is not so impactful towards our hypothesis.

For the component extraction, the absolute threshold was maintained at 0.4. The two extracted Components are labelled as Cognition (Component 1) and Affection (Component 2) based on the factors 
extracted in each of them. "Worry" is the sole factor extracted in the Affective component. The only factor that has a negative correlation with other factors in Cognitive component is "Irritation" (-0.453).

\section{Discussion and Implications}

Some researchers acknowledge the importance of personalized ads as an avenue to receive relevant product/service information, while others reflect onto the dangers of privacy violation. The intent of this research has been to understand the impact of various parameters related to personalized advertisements on social media and their subsequent impact on purchase intention of consumers as result of perception.

\begin{tabular}{|l|l|l|}
\hline \multicolumn{1}{|c|}{ Alternative Hypothesis } & Null Hypothesis \\
\hline H1 & Social Media Platforms' impact on Consumer Purchase Decisions & Accepted \\
\hline H2 & $\begin{array}{l}\text { Impact of frequency of personalized ads on social media, on consumer purchase } \\
\text { intention }\end{array}$ & Rejected \\
\hline H3 & $\begin{array}{l}\text { Impact of relevance and usefulness of personalized ads on social media, on } \\
\text { consumer purchase intention }\end{array}$ & Rejected \\
\hline H4 & Privacy violation concerns impact consumers' purchase intention & Rejected \\
\hline H5 & $\begin{array}{l}\text { Perception toward personalized ads on social media and its impact on consumer } \\
\text { purchase intention }\end{array}$ & Rejected \\
\hline
\end{tabular}

Table 1 Summary of Hypotheses

\subsection{Demographic Analysis}

Demographic data is vital to correlate the impact of personalized ads on consumer's purchase intentions, primarily because demography-based personalization and retargeting is heavily employed by marketers to heighten the relevance factor (Keyzer et al., 2015). When done right, this retargeting yields better results within higher engagement and increased sales/CTR (click-through-rates). An example of illtargeting is cited by Kim et al. (2018), wherein the supermarket giant Target Inc. randomly advertised pregnancy related coupons to teenagers as a promotional stint, leading to misinterpretation and indirect promotion of pregnancy amongst teenagers, that gave rise to controversies.

Gender based differences in opinions are well-established, but as Ruhrberg et al. (2017) define, the parameter of age is important to consider. They identified two generational cohorts, called Digital Natives (born 1978 or later) and Digital Immigrants (born before 1978). Since the reasons for using social media, or in general, digital technologies is distinct for these two groups, their perception regarding digital advertising is bound to vary and thus impact the goal of personalized advertising. They also reported a significant difference in how males and females perceive online advertisements and that women tend to have a higher tendency to be impacted by advertisements resulting in a purchase. Our research does indicate a stronger purchase intention of females, as compared to males, which is in total agreement with the results documented by Ruhrberg et al. (2017). Gender is a significant determinant in predicting traits, behaviours and performance. This data is hence invaluable for advertisers, as they assemble personalized ads based on various attributes specifically eliciting response on basis of gender (Jansen and Soloman, 2010). It's frequently reported by researchers that female-oriented key phrases as part of demographic targeting of personalized ads, generate more impressions and clicks than the male-oriented key phrases. This observation is crucial in understanding gender-specific ad targeting so as to boost engagement and subsequent sales (Jansen et al., 2013).

The high number of personalized ad encounters experienced by respondents on YouTube justifies the increased usage of platform by all age groups. Facebook, though, a pioneer of personalized advertising, with people accessing YouTube more frequently for purposes of entertainment, education and general surfing, is popular as an advertising platform. Instagram has been a platform for personalized advertising since it was taken-over by Facebook, which is in consensus with the observed results.

\subsection{Factors impacting Consumer Purchase I}

\subsubsection{Social Media Platforms}

The hypothesis formulation was on the basis of the belief that consumers' weed out personalized advertisements on the basis of the social media platform, as they believe a certain platform is more relevant or safe or beneficial to them. This favourable bias was tested and we found that consumers' purchase decisions don't necessarily depend on the social media platform. This finding is in contrast to a study by Voorveld et al. (2018), who report significant differences in perceptions towards advertisements as per ocil media platforms. Most of our respondents reported to have encountered personalized advertisements on YouTube, an observation quite distinct from other studies. This can be attributed to the increasing consumption of video format entertainment and infotainment. Increased viewership drives increasing interest by advertisers in utilizing these platforms. Dehgani et al., (2016) report that YouTube as an advertising channel has a positive element in terms of its utility but irritation negatively affects its ad impact. 


\subsubsection{Frequency of personalized advertisements}

The hypothesis constructed was based on the understanding that repeat exposures of personalized advertisements on social media could either boost the engagement or repel consumer interest as a result of irritation. It is widely believed that repeated exposure helps in building brand recall, a crucial parameter for converting sales prospect into a potential sale. Frequency of encountering personalized advertisements directly correlate to users' emotions about the platform. Lesser, more relevant and open-minded advertisements can propel the users' emotions positively (eg. Pinterest), while more frequent, less relevant and highly targeted advertisements could lead to negative emotional reaction from users (eg. YouTube, Facebook) (Voorveld et al., 2018).

Our finding that frequency of exposure to personalized advertisements on social media does influence the consumer purchase decisions is concurrent with several other studies. Pfiffelmann et al. (2020) reported a contrasting finding by tracking eye movements of consumers, wherein, they found that customers do not necessarily find personalized job advertisements attractive or unattractive based on frequency, but it does heighten the fixation towards ads. Raudeliuniene et al., (2018) identified frequency as a core element that influences advertising impact for ads on social media.

\subsubsection{Relevance and Usefulness of personalized advertisements}

Dynamic targeting and Retargeting are the facets of personalized advertisements where companies utilize the browsing behaviour of users to predict their interests and purchase patterns so as to target them better. Relevance plays a key role here, since lesser relevance or use to the user would often result in negative emotion towards the personalized ad (Keyzer et al., 2015). Hence, utilizing relevance and usefulness not only ensures that users are hooked better, but also reduces the companies' costs of customer search and acquisition (Frick, 2018). Practically, we can replace personalization with relevance as any brand/product advertised outside the interests and needs of a customer has extremely low chances of generating an intrinsic urge to buy the product/brand. Our findings that the customer purchase intention positively correlating to the relevance and usefulness metric of personalized advertisements on social media are concurrent with several other studies.

\subsubsection{Privacy violation concerns}

There is a lot of controversy hovering over the ethicality of acquiring, utilizing, and in some cases, sharing user data across firms for purposes of personalized advertising or data driven product innovation and marketing. As Karimi et al. (2017) mentions, permission marketing has now transpired into an act of consent, without being conscious of the permission being asked from. This manipulation and subsequent, disguised permission acquired, is through sheer "exploitation of inattention" and "cognitive laziness".

Our hypothesis was built on an overtly observed and discussed phenomenon amongst all age groups, regarding how personalized advertising is getting "creepy". John et al. (2018) calls this apprehension towards sharing privy data with companies as a "Privacy Paradox", explaining that humans have a tendency to cognitively choose whom to share information with or not. We might share physical intimacy details with a Medical Help App, but not wish to discuss it face-to-face with a medical personnel. There is a lot of supportive data available for our finding that privacy concerns do largely impact the customers' purchase intentions (Strycharz et al., 2019; Kim et al., 2018; Yu J., 2011). Many consumer research studies have repeatedly highlighted that customers do indeed feel uncomfortable with personalized advertising and tend to reject it, but on the other hand, marketers' data and follow-up consumer buying decision studies reflect the success of personalized advertising in boosting engagement and sales (Boerman et al., 2017; Strycharz et al., 2019).

\subsection{Perception towards personalized ads on social media and its impact on consumer purchase intention}

We were able to identify two principal components, viz., Cognitive and Affective, with the aid of seven statements that ranged from simple low-involvement decisions like "how easy a product purchase is when it directly appears as a personalized advertisement", to a high-involvement parameter of privacy. We were hence able to cover multiple key perceptions and concerns that a social media user may feel when confronted with a personalized ad with a high relevance. The perception of personalized advertising on social media is quite split due to certain proportion of consumers reporting that they like receiving such ads as its more relevant and useful to them (O'Donnell and Cramer, 2015).

\begin{tabular}{|l|l|c|c|}
\hline \multicolumn{2}{|c|}{ Extracted Components } & $\begin{array}{c}\text { Positive } \\
\text { Correlation }\end{array}$ & $\begin{array}{c}\text { Negative } \\
\text { Correlation }\end{array}$ \\
\hline \multirow{4}{*}{ Component 1 } & \multirow{3}{*}{ Cognitive Component } & Ease & \\
\cline { 3 - 3 } & & Introduction & \multirow{3}{*}{ Irritation } \\
\cline { 3 - 3 } & & Loyalty & \\
\cline { 3 - 3 } & & Trust & \\
\cline { 3 - 3 } & & Interest & \\
\hline Component 2 & Affective Component & Worry & \\
\hline
\end{tabular}

Table 11 Components extracted by PCA 
Our extracted components do justify this difference in opinion from the same pool of respondents. "Ease of purchase" and "Introduction to new brands/products" are fairly low involvement responses, which received a higher score, while, "trust and Loyalty" towards the advertised brands is fairly subjective as it either stems from extrinsic view or prior experience. The "Interest" factor is attributed to the relevance and usefulness of personalized advertisements on social media (refer H3). The "Worry" factor correlates directly to the privacy concerns that customers harbour towards personalized advertising (refer H5), but also due to their inability to confirm the online advertisements' claim in person. The most interesting observation though is "Irritation" as having a negative correlation to the Cognitive Component. "Irritation" could be justified as having a strong negative impact on customers' trust and loyalty towards a particular brand/product. In conjunction, studies do report irritation as a negative effect as observed by social media users, along with reactance and avoidance (Kasper et al., 2019). Several of our respondents claim that irritation is prima facie a reaction to (i) repetition and, (ii) heightened relevance.

\section{Limitations of the Study}

We limited the demographic data collection to gender, age, education status and social media awareness/usage as per the pool of participants we intended to approach. One key criteria missing is the income profile of our respondents. Since convenience sampling technique was employed, we were unable to construct a predefined set of participation that would have enabled us to define the impact of certain factors more cohesively. We decidedly focused on only six social media apps that are popular in India, hence excluding other platforms providing advertising facilities. Hence, our study might be limited in its scope to project the personalized social media advertising potential across all possible social media apps.

\section{Conclusion}

Newer social media platforms are gaining popularity (eg. TikTok) and opening up prospective channels for marketers, courtesy the increasing user base. Advertisers are swearing by the utility of personalized advertisements as past data is evidence of its wonders. Personalization would not cease, but firms need to tread the safety line in determining how to effectively target consumers by using dynamic data, without negatively influence them through "over-personalization". Privacy controls need to be upgraded so as to present customers with permission controls, which shall not only be ethically valiant, but shall reap fruits by gaining consumer trust.

Our study could not establish the influence of various social media platforms as a moderating factor in shaping up consumers' perception of personalized advertising, but it clearly establishes the impact of frequency, relevance and usefulness of advertisements, related privacy concerns, as well as, factors contributing to perception development in facilitating consumers' purchase intentions. Generally, customers do not get bothered by personalized advertising content. Our study infers that advertisements indeed positively steer customers' purchase intentions by being highly relevant, useful and informative. But, the concerns shown by customers towards personalized advertisements should not be neglected, as they would only increase and lead to failure of the personalization and dynamic retargeting mechanism in the long run.

\section{References}

1. Balakrishnan, B. K., Dahnil, M. I., \& Yi, W. J. (2014). The Impact of Social Media Marketing Medium toward Purchase Intention and Brand Loyalty among Generation Y. Procedia - Social and Behavioral Sciences, 148, 177-185. doi: 10.1016/j.sbspro.2014.07.032

2. Belch, G. E., \& Belch, M. A. (2012). Advertising and promotion: an integrated marketing communications perspective. New York: McGraw-Hill Irwin.

3. Bleier, A., \& Eisenbeiss, M. (2015). Personalized Online Advertising Effectiveness: The Interplay of What, When, and Where. Marketing Science, 34(5), 669-688. doi: 10.1287/mksc.2015.0930

4. Boerman, S. C., Kruikemeier, S., \& Borgesius, F. J. Z. (2017). Online Behavioral Advertising: A Literature Review and Research Agenda. Journal of Advertising, 46(3), 363-376. doi: 10.1080/00913367.2017.1339368

5. Carrillat, F. A., D'Astous, A., \& Grégoire, E. M. (2014). Leveraging social media to enhance recruitment effectiveness. Internet Research, 24(4), 474-495. doi: 10.1108/intr-07-2013-0142

6. Chourasiya, A. (2017). Online Marketing: Impact on society. International Journal of Engineering Development and Research, 5(2), 1519-1521. Retrieved from https://www.ijedr.org/papers/IJEDR1702239.pdf

7. Dehghani, M., Niaki, M. K., Ramezani, I., \& Sali, R. (2016). Evaluating the influence of YouTube advertising for attraction of young customers. Computers in Human Behavior, 59, 165-172. doi: 10.1016/j.chb.2016.01.037

8. Digital Advertising - India: Statista Market Forecast. (n.d.). Retrieved March 3, 2020, from https://www.statista.com/outlook/216/119/digital-advertising/india

9. Duffett, R. G. (2015). Facebook advertising's influence on intention-to-purchase and purchase amongst Millennials. Internet Research, 25(4), 498-526. doi: 10.1108/intr-01-2014-0020

10. Frick, T. W. (2018). The Implications of Advertising Personalization for Firms, Consumers, and Ad Platforms. Retrieved from http://hdl.handle.net/1765/110314

11. Gaber, H. R., Wright, L. T., \& Kooli, K. (2019). Consumer attitudes towards Instagram advertisements in Egypt: The role of the perceived advertising value and personalization. Cogent Business \& Management, 6(1). doi: 10.1080/23311975.2019.1618431

12. Hashim, N. H., Normalini, \& Sajali, N. (2018). The Influence Factors Towards Mobile Advertising Message Content on Consumer Purchase Intention. Global Business Review, 19(5), 1187-1206. doi: 10.1177/0972150918788746 
13. Jansen, B. J., \& Solomon, L. (2010). Gender demographic targeting in sponsored search. Proceedings of the 28th International Conference on Human Factors in Computing Systems - CHI 10. doi: 10.1145/1753326.1753448

14. Jansen, B. J., Moore, K., \& Carman, S. (2013). Evaluating the performance of demographic targeting using gender in sponsored search. Information Processing \& Management, 49(1), 286-302. doi: 10.1016/j.ipm.2012.06.001

15. Johansson, C., \& Wengberg, P. (2017). Dynamic Retargeting (dissertation). Retrieved from http://www.divaportal.org/smash/get/diva2:1115437/FULLTEXT01.pdf

16. John, L. K., Kim, T. K., \& Barasz, K. K. (2018a). Ads That Don't Overstep. Harvard Business Review. Retrieved from https://hbr.org/2018/01/ads-that-dont-overstep

17. Karimi, S., Stoev, Y. G., \& Zander, O. (2017). Ethical Issues in E-Permission Marketing (dissertation). Retrieved from http://www.divaportal.org/smash/get/diva2:1111628/FULLTEXT01.pdf

18. Kaspar, K., Weber, S. L., \& Wilbers, A.-K. (2019). Personally relevant online advertisements: Effects of demographic targeting on visual attention and brand evaluation. Plos One, 14(2). doi: 10.1371/journal.pone.0212419

19. Keyzer, F., Dens, N. \& Pelsmacker, P. (2015) Is This For ME? How Consumers Respond to Personalized Advertising on Social Network Sites. Journal of Interactive Advertising, 15(2), 1-11, doi: 10.1080/15252019.2015.1082450

20. Kim, T., Barasz, K., \& John, L. K. (2018b). Why Am I Seeing This Ad? The Effect of Ad Transparency on Ad Effectiveness. Journal of Consumer Research, 45(5), 906-932. doi: 10.1093/jcr/ucy039

21. Lavrakas, P. J. (2008). Convenience Sampling - SAGE Research Methods. Retrieved March 19, 2020, from https://methods.sagepub.com/reference/encyclopedia-of-survey-research-methods/n105.xml

22. Mack, S. (2015, September 14). How social media has left us with a lower attention span than a goldfish. Retrieved March 29, 2020, from https://www.fq.co.nz/culture/whats-on/how-social-media-has-left-us-with-a-lower-attention-span-than-a-goldfish

23. Maoyan, Zhujunxuan \& Sangyang (2014). Consumer Purchase Intention Research Based on Social Media Marketing. (2014). International Journal of Business and Social Science, 5(10), 92-97. Retrieved from https://docplayer.net/7137108-Consumerpurchase-intention-research-based-on-social-media-marketing.html

24. Oberlo.in (2020) - 1010 Social Media Statistics You Need to Know in 2020 (Infographic), Retrieved on March 3, 2020, from https://www.oberlo.in/blog/social-media-marketing-statistics

25. O'Donnell, K., \& Cramer, H. (2015). People's Perceptions of Personalized Ads. Proceedings of the 24th International Conference on World Wide Web - WWW 15 Companion, 1293-1298. doi: 10.1145/2740908.2742003

26. Pfiffelmann, J., Dens, N., \& Soulez, S. (2020). Personalized advertisements with integration of names and photographs: An eye-tracking experiment. Journal of Business Research, 111, 196-207. doi: 10.1016/j.jbusres.2019.08.017

27. Quick, T. (2020) The Evolution of Advertising \& How Personalization Improved Over Time. (2020, January 28). Retrieved March 20, 2020, from https://instapage.com/blog/evolution-of-advertising

28. Raudeliuniene, J., Davidaviciene, V., Tvaronaviciene, M., \& Jonuska, L. (2018). Evaluation of Advertising Campaigns on Social Media Networks. Sustainability, 10(4), 973. doi: 10.3390/su10040973

29. Ruhrberg, S. D., Kirstein, G., \& Baran, K. S. (2017). User Acceptance of Personalized and Context-Specific Online Advertising. Open Journal of Social Sciences, 05(03), 223-232. doi: 10.4236/jss.2017.53020

30. Sannam S4 (2020) Top Social Media Trends in 2020. Retrieved March 27, 2020, from https://sannams4.com/top-social-media-trends-inindia-2020/

31. Strycharz, J., Noort, G. V., Smit, E., \& Helberger, N. (2019). Protective behavior against personalized ads: Motivation to turn personalization off. Cyberpsychology: Journal of Psychosocial Research on Cyberspace, 13(2). doi: 10.5817/cp2019-2-1

32. Tucker, C. E. (2013). Social Networks, Personalized Advertising, and Privacy Controls. Journal of Marketing Research, 51(5), 546-562. doi: 10.1509/jmr.10.0355

33. Voorveld, H. A. M., Noort, G. V., Muntinga, D. G., \& Bronner, F. (2018). Engagement with Social Media and Social Media Advertising: The Differentiating Role of Platform Type. Journal of Advertising, 47(1), 38-54. doi: 10.1080/00913367.2017.1405754

34. Yu, J. (2011). Is it worth it to be unethical? Consumers' attitudes toward personalized commercial e-mails. Journal of Database Marketing \& Customer Strategy Management, 18(4), 274-285. doi: 10.1057/dbm.2011.38 